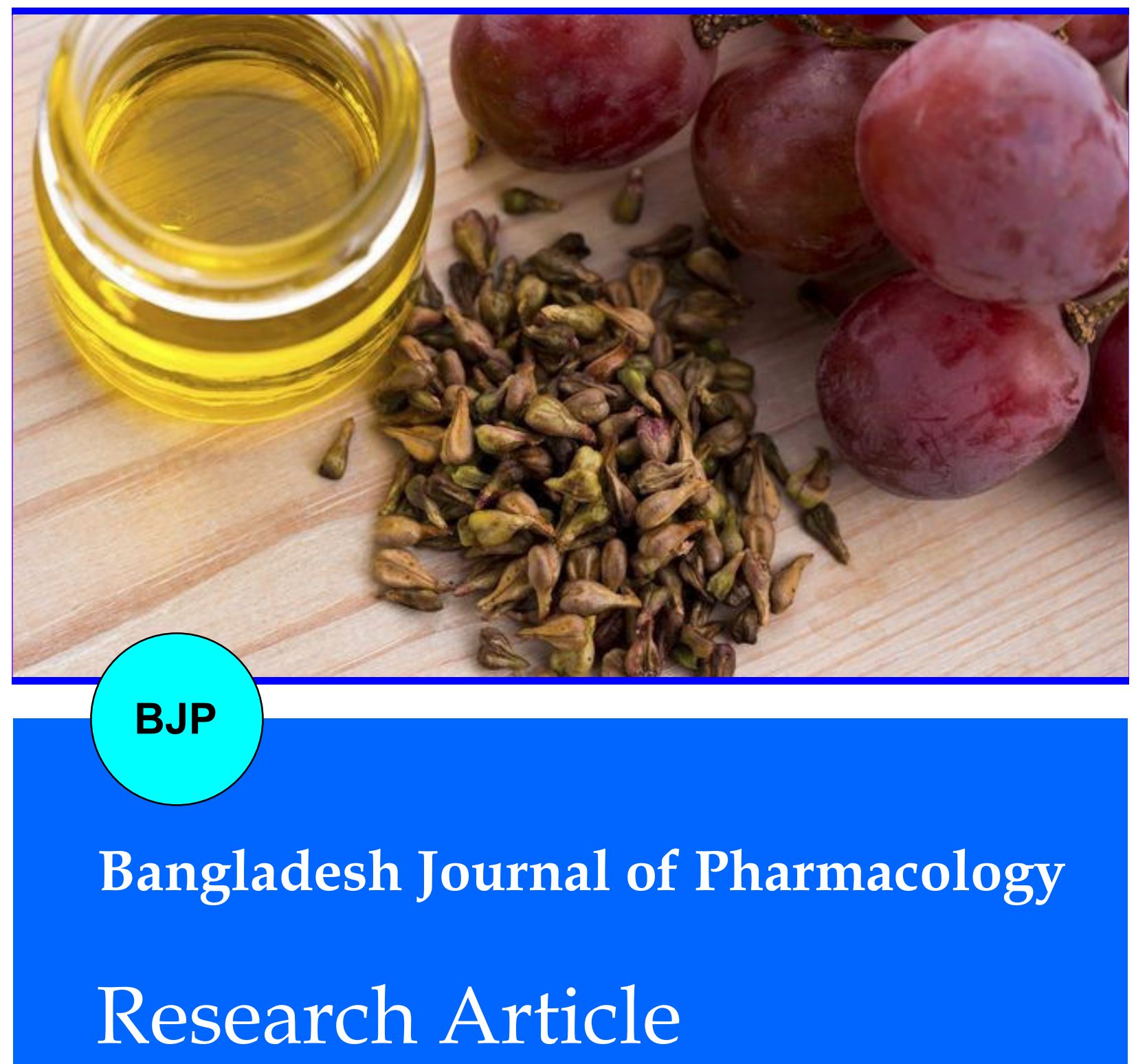

Study of antidepressant effects of grape seed oil in male mice using tail suspension and forced swim tests 


\title{
Study of antidepressant effects of grape seed oil in male mice using tail suspension and forced swim tests
}

\author{
Zahra Rabiei, Sajad Naderi and Mahmoud Rafieian-Kopaei
}

Medical Plants Research Center, Basic Health Sciences Institute, Shahrekord University of Medical Sciences, Shahrekord, Iran.

\begin{tabular}{|c|c|}
\hline \multicolumn{2}{|l|}{ Article Info } \\
\hline Received: & \\
\hline Accepted: & $10 \mathrm{O}$ \\
\hline Available Online: & 5 November 201 \\
\hline \multicolumn{2}{|c|}{ DOI: $10.3329 /$ bjp.v12i4.33520 } \\
\hline \multicolumn{2}{|c|}{$\begin{array}{l}\text { Cite this article: } \\
\text { Rabiei Z, Naderi S, Rafieian-Kopae } \\
\text { M. Study of antidepressant effects of } \\
\text { grape seed oil in male mice using tai } \\
\text { suspension and forced swim tests } \\
\text { Bangladesh J Pharmacol. 2017; 12: } 397 \\
-402 \text {. }\end{array}$} \\
\hline
\end{tabular}

\begin{abstract}
The aim of this study was to investigate the antidepressant effects of grape seed oil in male mice $(n=60)$ using tail suspension and forced swim tests. Mice were divided to six groups of 10 in each group. Group I: Intraperitoneally receiving normal saline; Group II: Received normal saline \& stress; Group IIIV: Injected (i.p.) with different $(60,120$, and $240 \mathrm{mg} / \mathrm{kg})$ doses of grape seed oil; and Group VI: Received fluoxetine $(10 \mathrm{mg} / \mathrm{kg})$. Grape seed oil in $60 \mathrm{mg} /$ $\mathrm{kg}$ significantly decreased immobility time in tail suspension and forced swim tests under chronic unpredictable stress compared to groups under chronic stress receiving normal saline and grape seed oil (120 and $240 \mathrm{mg} / \mathrm{kg}$ ). Grape seed oil $(60 \mathrm{mg} / \mathrm{kg})$ significantly improved the motor balance in mice under chronic stress. It had no significant effect on serum corticosterone level. Grape seed oil can improve depression symptoms in mice.
\end{abstract}

\section{Introduction}

Depression is a multifactorial, chronic, and life-threatening disorder with high prevalence rate worldwide. People with major depression have been reported to have different levels of oxidative stress and decrease in antioxidant enzymes (Sarandol et al., 2007). Studies have indicated that some antidepressants can reduce certain oxidative stress markers and cause increase in internal antioxidants. Currently, there are almost 30 different types of antidepressants. Basically, these drugs cause certain adverse effects due to their effects on various neuromediators. Now-a-days, researchers are considering natural, plant-based compounds due to numerous adverse effects of chemical antidepressants (Rabiei and Rabiei, 2017; Aslam and Sultana, 2015).

Grape seed oil is prepared by squeezing and refining of fresh grape seed and its nutritional properties are comparable to those of olive oil. Chemically, there are high amounts of essential fatty acids and fat soluble vitamins in this oil. This oil is sodium and calcium-free and the amount of its unsaturated fatty acids may reach to $90 \%$. Grape seed oil is often produced from the wastes of the grapevine or fermentation beverage factories, and has many properties (Movahed and Ghavami, 2007).

Grape seed oil contains high concentrations (68-76\%) of linoleic acid. Linoleic acid is an essential fatty acid of the human body and is nutritionally essential for functioning of tissues and maintenance of the body. Because grape seed oil naturally has no cholesterol, it is helpful in reducing the risk of heart diseases and other circulatory disorders (Ismail et al., 2015).

Grape seed oil contains proanthocyanidine compounds that are considered a group of bioflavonoid anti-oxidants. These compounds reduce the risk of cardiovascular diseases, stroke, and cancer, and most importantly, decrease LDL and increase HDL. These properties are unique to grape seed oil (Beveridge et al., 2005). Grape seed oil contains 60-120 mg vitamin E, one of the most potent natural antioxidants. It is not, therefore, 
necessary to add artificial antioxidants such as butylated hydroxytoluene and tert-butylhydroquinone to grape seed oil. Grape seed oil, as with other vegetable oils, such as palm oil or coconut oil, contains natural tocoterienols. These compounds have a much higher antioxidant potential than tocopherols. Therefore, despite being highly unsaturated, grape seed oil is stable against oxidation due to above mentioned stabilizing compounds (Beveridge et al., 2005).

Given harmful effects of chemical drugs, endeavours have been started to seek out sedative and antidepressant medications with fewer side effects, and in this regard, the production of herbal medicines has been expanded. It is also determined that if a plantbased medication is used with other compounds in that plant, it causes less side effects. Considering the beneficial effects of grape seed oil on the nervous system, we investigated its antidepressant effects in vitro.

\section{Materials and Methods}

\section{Laboratory animals}

Male mice $(n=60)$ weighing $25 \pm 30 \mathrm{~g}$ were used. The mice were maintained in the animal house of the Shahrekord University of Medical Sciences under $24^{\circ} \mathrm{C}$ temperature and 12 hours dark/light cycle with free access to water and food. In addition, each mouse was tested only once.

\section{Induction of depression and grouping}

In this study, depression was induced by exposure to chronic stress. According to the standard method of Kumar et al. (2011), mice were exposed to one of the stressful factors below daily for 3 weeks (Kumar et al., 2011):

A: Swimming in cold water $\left(12^{\circ} \mathrm{C}\right)$ for $5 \mathrm{~min}$; A1: Swimming in water with room temperature $\left(23 \pm 2{ }^{\circ} \mathrm{C}\right)$ for $10 \mathrm{~min}$; A2: Swimming in water with room temperature $\left(23 \pm 2^{\circ} \mathrm{C}\right)$ for 15 min; B: Tail pinch (30 sec); B2: Tail pinch (60 sec); B3: Tail pinch (90 sec); C: Water and food deprivation (24 hours); D: Overnight awakening; E: No stress.

Mice were divided to six groups of 10 each: Group I: Intraperitoneally received normal saline; Group II: Received normal saline and stress; Groups III-V: Intraperitoneally injected with different $(60,120$, and 240 $\mathrm{mg} / \mathrm{kg}$ ) doses of grape seed oil; and Group VI: Received fluoxetine $(10 \mathrm{mg} / \mathrm{kg})$.

\section{Tail suspension test}

In tail suspension test used to assess the depression levels, metal bars of $70 \mathrm{~cm}$ high are used, a $50 \mathrm{~cm}$ rope is longitudinally stretched between them, and mouse tail is closed by the rope and the mouse is hanged up from its tail. The test begins with jerking mice. When mouse becomes completely inactive and immobile and exhibits no reaction, it is considered immobility. Total duration of tail suspension test, as with forced swim test, is $6 \mathrm{~min}$ and the first $2 \mathrm{~min}$ is specified to animal's adaptation to the apparatus. The immobility time (s) in the following $4 \mathrm{~min}$ was recorded by chronometer. All tests of variables were recorded by one person (Gupta et al., 2016).

\section{Forced swim test}

This animal test is one of the most reliable and common tests for evaluation of depression. Based on learned helplessness of Martin seligman, if animal is exposed to chronic stress and fails to escape, it gradually loses its hope to escape, stops its activity and mobility, and becomes frustrated and immobile. To measure the immobility time, all time intervals when mouse is immobile are recorded within a specified duration. Extended immobility time represents depression and its decrease does the efficacy of treatment with antidepressant. In this test, a glass container that has a length of $25 \mathrm{~cm}$, a width of $12 \mathrm{~cm}$, and a height of $15 \mathrm{~cm}$ is filled with $25^{\circ} \mathrm{C}$ water and the mouse from a $20-\mathrm{cm}$ distance to the water surface is slowly placed in the water. Conventionally, lack of paddling is considered immobility. All chronological measurements were conducted by one person. Total forced swim test lasts for $7 \mathrm{~min}$ and the first $3 \mathrm{~min}$ are specified for adaptation to test condition and therefore immobility time during this period is not recorded. All tests of variables were recorded by one person (Gupta et al., 2016).

\section{Rotarod test}

Rotarod apparatus was used to assess balance maintenance and resistance to movement. This apparatus has a rotator with rotation speed of 4,000 rpm. This apparatus has a belt and rotation speed is adjusted by moving it on the place of belt position. The mice were first placed on the rotarod roller rod and trained to move on it based on the main protocol (speed: $10 \mathrm{rpm}$ and acceleration: $7 \mathrm{rpm}^{2}$ ), and the balance test was performed 30 min later. All mice were placed on the rotarod 1 hour after injection of the extract. The period when mouse could maintain its balance and resist against the movement of the rotarod was considered resistance time. The maximum test time for each mouse was considered 300 sec (Rabiei et al., 2016).

\section{Measuring plasma corticosterone level}

Blood samples (0.5 to $0.8 \mathrm{~mL}$ ) were taken 1 hour after conducting the behavioral tests, and the plasma corticosterone levels were measured (Harati et al., 2014).

\section{Data analysis}

Statistical analysis was conducted using SPSS 16. To investigate the significant difference between the groups, one-way ANOVA and then Duncan's test were 
used. Data expressed as mean \pm standard deviation and $\mathrm{p}<0.05$ was considered significance level.

\section{Results}

Effect of grape seed oil on immobility time in tail suspension test

Figure 1 illustrates the effect of intraperitoneal injection of fluoxetine and different doses of grape seed oil on immobility time in tail suspension test. As illustrated, the immobility time in the group under stress receiving normal saline was significantly higher than that in the control group $(\mathrm{p}<0.05)$. Immobility duration significantly increased in the group under stress receiving grape seed oil $(240 \mathrm{mg} / \mathrm{kg})$ compared to the other groups $(\mathrm{p}<0.05)$. There was no significant difference in immobility time between the groups under stress receiving normal saline and those injected with grape seed oil $(120$ and $240 \mathrm{mg} / \mathrm{kg})(\mathrm{p}<0.05)$. Intraperitoneal injection of grape seed oil $(60 \mathrm{mg} / \mathrm{kg})$ significantly decreased immobility time compared to normal saline and grape seed oil (120 and $240 \mathrm{mg} / \mathrm{kg}$ ) in the mice under stress $(\mathrm{p}<0.05)$.

Intraperitoneal injection of fluoxetine $(10 \mathrm{mg} / \mathrm{kg})$ significantly decreased the immobility time compared to normal saline and grape seed oil $(60,120$, and $240 \mathrm{mg} /$ $\mathrm{kg})$ in the mice under stress $(\mathrm{p}<0.05)$.

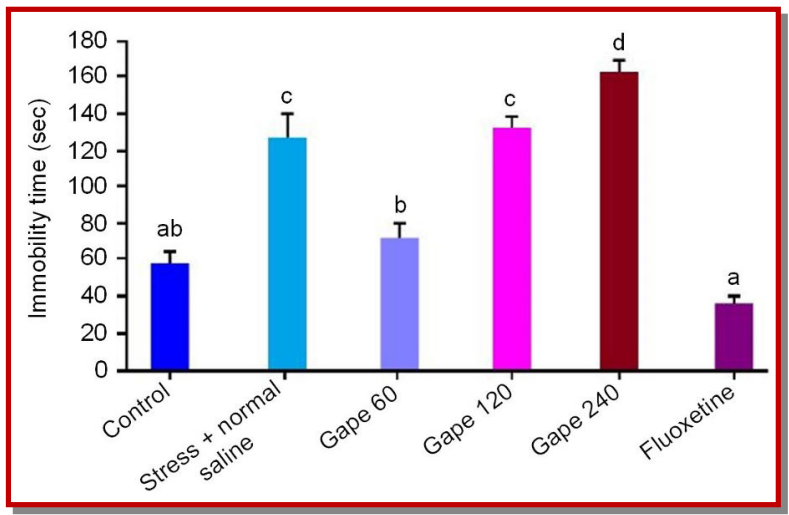

Figure 1: Effect of intraperitoneal injection of fluoxetine and different doses of grape seed oil on immobility time in tail suspension test. a: Significant difference compared ' $b$ ', ' $c$ ' and ' $d$ '; b: Significant difference compared ' $a$ ', ' $c$ ' and ' $d$ '; c: Significant difference compared ' $a$ ', ' $b$ ' and ' $d$ '; d: Significant difference compared to ' $a$ ', ' $b$ ' and ' $c$ ' $(p<0.05)$; ab: No significant difference

\section{Effect of grape seed oil on immobility time in forced swim test}

Figure 2 illustrates the effect of intraperitoneal injection of fluoxetine and different doses of grape seed oil on the immobility time in forced swim test. As illustrated, the immobility time in group under chronic stress receiving normal saline was significantly higher than that in the control group $(\mathrm{p}<0.05)$. As illustrated, there was no significant difference among the groups under chronic stress receiving 120 and $240 \mathrm{mg} / \mathrm{kg}$ doses of grape seed oil and the group under chronic stress receiving normal saline $(\mathrm{p}<0.05)$. Intraperitoneal injection with fluoxetine $(10 \mathrm{mg} / \mathrm{kg})$ significantly decreased the immobility time compared to normal saline and grape seed oil (120 and $240 \mathrm{mg} / \mathrm{kg}$ ) in the mice under stress $(p<0.05)$. Intraperitoneal injection of grape seed oil $(60 \mathrm{mg} / \mathrm{kg})$ significantly decreased the immobility time compared to normal saline and grape seed oil (120 and $240 \mathrm{mg} / \mathrm{kg})$ in the mice under stress $(\mathrm{p}<0.05)$.

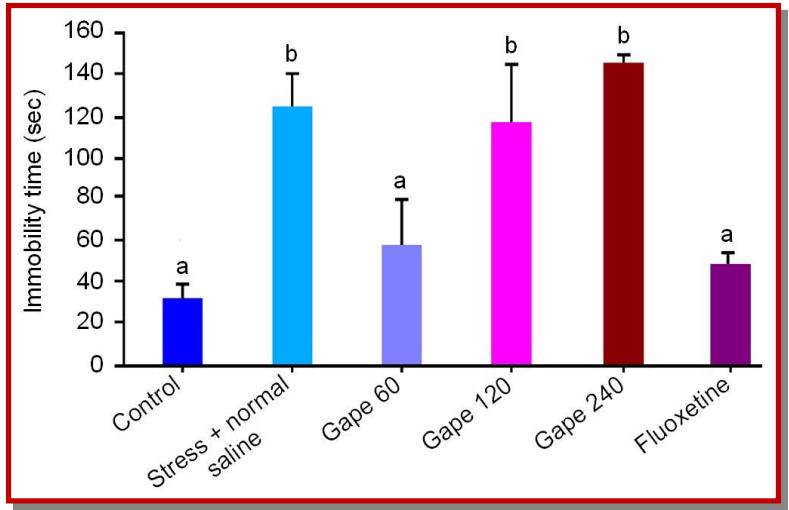

Figure 2: The effect of intraperitoneal injection of fluoxetine and different doses of grape seed oil on immobility time in forced swimming test; difference is considered significant at $\mathrm{p}<0.05$

\section{Psychomotor coordination by rotarod treadmill apparatus}

The ability to maintain balance and resist movement was investigated using rotarod (Figure 3). Resistance to rotation in groups under stress receiving fluoxetine and grape seed oil $(60 \mathrm{mg} / \mathrm{kg}$ ) was significantly higher than that in the normal saline group $(\mathrm{p}<0.05)$. There was no significant difference in the time of resistance to rotation between group under stress receiving grape seed oil (120 and $240 \mathrm{mg} / \mathrm{kg}$ ) and group under stress treated with normal saline. The time of resistance to rotation was significantly higher in the control group than the group under chronic stress.

\section{Effect of grape seed oil on serum corticosterone level}

Figure 4 shows the results related to the effect of grape seed oil on serum corticosterone levels in different groups. The serum corticosterone levels were significantly higher in the group under chronic unpredictable stress compared to the control group $(\mathrm{p}<0.05)$. Treatment with grape seed oil (60 and 120 $\mathrm{mg} / \mathrm{mL}$ ) and fluoxetine caused no significant effect on serum corticosterone levels in mice under chronic unpredictable stress $(p>0.05)$. Serum corticosterone levels decreased in the group receiving grape seed oil 
(240 mg/mL), but did not significantly change compared to the control group and the group under chronic unpredictable stress.

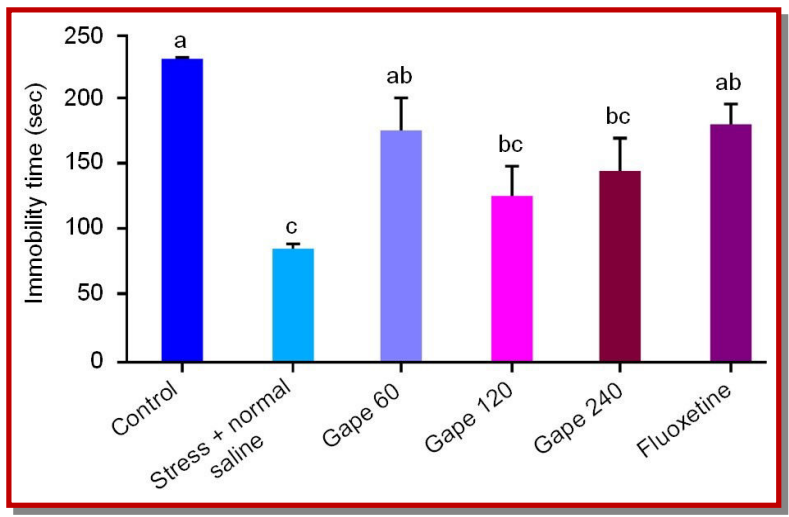

Figure 3: Effect of intraperitoneal injection of fluoxetine and different doses of grape seed oil on balance maintenance and resistance to movement

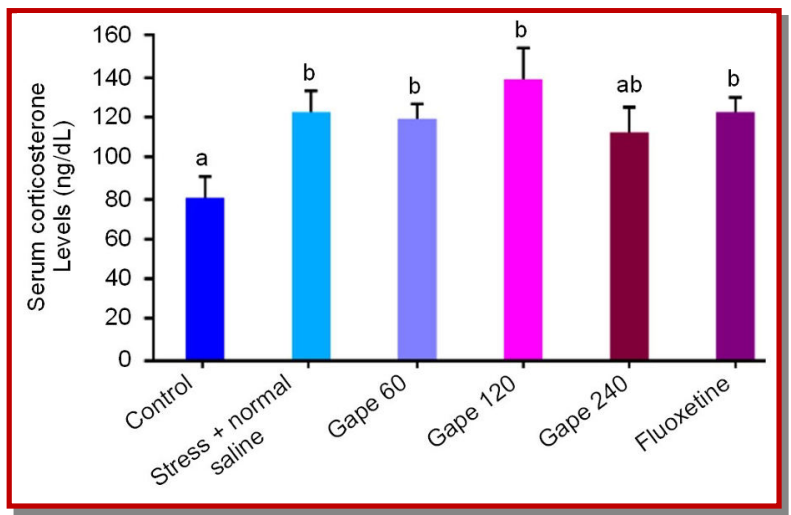

Figure 4: Effect of intraperitoneal injection of different doses of fluoxetine and grape seed oil on serum corticosterone levels

\section{Discussion}

This study investigated the effect of grape seed oil (60, 120 and $240 \mathrm{mg} / \mathrm{kg}$ ) on the symptoms of depression induced by chronic unpredictable stress in mice. In addition, this study evaluated the effects of grape seed oil on motor coordination and serum corticosterone levels in mice under chronic stress. According to the results, immobility time in forced swim test and TST in control group was significantly lower than under-stress group. Injection of grape seed oil $(60 \mathrm{mg} / \mathrm{kg})$ to mice under chronic stress significantly decreased immobility time in forced swim test and tail suspension test compared to groups under chronic stress receiving normal saline and grape seed oil (120 and $240 \mathrm{mg} / \mathrm{kg}$ ). In this study, injection of fluoxetine $(10 \mathrm{mg} / \mathrm{kg})$ to mice under chronic stress significantly decreased the immobility time compared to the group under chronic stress receiving normal saline. Moretti et al. consistently showed that intraperitoneal injection of fluoxetine (10 $\mathrm{mg} / \mathrm{kg}$ ) to mice under chronic unpredictable stress significantly decreased the immobility time in forced swim test and tail suspension test (Moretti et al., 2012). Kumar et al. (2011) also reported positive effects of fluoxetine on mild and chronic unpredictable stress (Kumar et al., 2011).

Studies have shown that most symptoms of chronic unpredictable stress-induced depression occur due to the impairment of neuroendocrine, antioxidant defense, and inflammatory systems (Eren et al., 2007; Mao et al., 200; Marks et al., 2009; You et al., 2011). A study by Schaalan et al. (2011), reported neuroendocrine impairment and significant increase in serum adrenocorticotropin and corticosterone levels in mice exposed to chronic unpredictable stress (Schaalan and Nassar, 2011). Mao et al. (2009) reported increase in serum corticosteroids levels in mice under chronic unpredictable stress (Mao et al., 2009). A study by Grundmann et al. (2010) has shown chronic stressinduced depression in mice caused increase in serum adrenocorticotropin and corticosterone levels (Grundmann et al., 2010).

In Marks et al study, frequent administration of corticosterone led to significant increase in depressivelike behaviors in forced swim test in mice. These behaviors were independent of changes in motor activity or muscular strength (Marks et al., 2009). Chronic stress-induced depression, in our study, caused significant increase in serum corticosterone levels. The administration of grape seed oil $(60,120$, and $240 \mathrm{mg} /$ $\mathrm{kg}$ ) did not have a significant effect on serum corticosterone levels, although this extract in $240 \mathrm{mg} /$ $\mathrm{kg}$ concentration decreased its level yet insignificantly; therefore, it seems that other mechanisms are involved in antidepressant effects of grape seed oil. The role of inflammatory mechanisms in chronic unpredictable stress-induced depression has been reported in different studies.

In a study, mice were exposed to chronic unpredictable stress, and results showed increased serum levels of tumor necrosis alpha (TNFa) (Schaalan and Nassar, 2011). It was reported that the expression of proinflammatory cytokines such as TNFa, interleukin-6, and interleukin- 1 beta significantly increased in the brain and spleen of mice under chronic stress, and expression of anti-inflammatory cytokines such as TGF$\beta$ and interleukin-10 significantly decreased (You et al., 2011).

Chronic stress-induced depression increased the levels of inflammatory markers, interleukin-6, and TNFa (Grundmann et al., 2010). Given the anti-inflammatory effects of grape seed oil confirmed in previous studies, it can be argued that grape seed oil can significantly inhibit depression due to chronic stress through decreasing the levels of inflammatory mediators. 
In an experimental study, in mice treated with carbon tetrachloride through grape seed oil, brain TNFa and interleukin-6 levels decreased significantly (Ismail et al., 2015). The effect of procyanidine of grape seed on corticosterone-induced ear edema and carrageenainduced foot swelling has been demonstrated. Procyanidins of grape seed significantly decreased nitric oxide level, nitric oxide synthase activity, and TNFa, interleukin-1 beta, and prostaglandin E2 levels (Li et al., 2000).

The role of oxidative stress has been demonstrated in UCS-induced depression in different studies. In Schaalan et al study, chronic unpredictable stress was associated with decrease in antioxidant activity of superoxide dismutase and glutathione reductase, and a decrease in glutathione levels in mice hippocampus. In addition, it was observed that lipids peroxidation and lactate dehydrogenase levels increased in the hippocampus of mice exposed to chronic unpredictable stress (Schaalan and Nassar, 2011). Induction of depression using chronic stress model significantly reduced activity of glutathione peroxidase in mouse brain cortex. The induction of depression also reduced the levels of glutathione and vitamin $\mathrm{C}$ in the cortex and increased lipids peroxidation (Eren et al., 2007).

Increase in proteins peroxidation in the frontal lobe of the brain, hippocampus, and striatum caused increase in lipid peroxidation in the cerebellum and corpus striatum, and decrease in activity of superoxide dismutase in the frontal lobe of the brain, hippocampus, and striatum of mice exposed to chronic unpredictable stress (Lucca et al., 2009). In a study by Grundmann et al. (2010), chronic stress-induced depression caused decrease in antioxidant capacity and activity of glutathione per-oxidase, superoxide dismutase and catalase in the hippocampus and hypothalamus (Grundmann et al., 2010). Given the antioxidants effects of grape seed oil in different studies, it seems that grape seed oil significantly inhibits chronic unpredictable stress-induced depression through decreasing the oxidative stress markers in the brain.

In the study, proanthocyanidine, vitamin C, vitamin $E$, succinate, and beta-carotene of grape seed significantly inhibited lipid peroxidation and oxidative stress of brain cells' DNA by oxygen free radicals (Bagchi et al., 1998).

There was significant protective effects of grape seed against the oxidative damage of DNA in the brain neuronal cells using ethanol (Guo et al., 2007).

Grape seed oil significantly increased the activity of superoxide dismutase, catalase, glutathione peroxidase, and brain glutathione content in mice treated with carbon tetrachloride (Ismail et al., 2015). Treatment of grape seed oil-receiving mice with tetrachloride signifi- cantly decreased their brain malondialdehyde levels.

In addition, the protective effects of vitamin $C$ against chronic unpredictable stress-induced depression was reported. The mechanism of antidepressant effects of ascorbic acid is due to the reduction of oxidative stress parameters (Moretti et al., 2012).

Vitamin E reduces the levels of depression in women with periodic chest pain by decreasing the oxidative stress markers (Momeni, 2012). As grape seed oil contains high amounts of vitamin $\mathrm{E}$ and $\mathrm{C}$, it seems that reduction of oxidative stress parameters is one of the main involved mechanisms in antidepressant effects of this oil; however, it is recommended to investigate this assumption by measuring the levels of oxidative stress markers in additional studies.

\section{Conclusion}

Administration of grape seed oil caused antidepressant effects and significantly increased immobility time in forced swim test and tail suspension test in depressed mice. In addition, grape seed oil increased motor coordination of mice. It seems that antidepressant effects of grape seed oil extract are due to antioxidant and anti-inflammatory mechanisms.

\section{Financial Support}

Self-funded

\section{Ethical Issue}

The study was approved by the Ethical Committee of the Shahrekord University of Medical Sciences.

\section{Conflict of Interest}

All authors have completed the ICMJE uniform disclosure form and declare no support from any organization for the submitted work.

\section{References}

Aslam M, Sultana N. Vitis vinifera juice ameliorates depression-like behavior in mice by modulating biogenic amine neurotransmitters. Bangladesh J Pharmacol. 2015; 10: 753-58.

Bagchi DA, Garg R, Krohn M, Bagchi D, Bagchi J, Balmoori, Stohs S. Protective effects of grape seed proanthocyanidins and selected antioxidants against TPA-induced hepatic and brain lipid peroxidation and DNA fragmentation, and peritoneal macrophage activation in mice. Gen Pharmacol Vasc S. 1998; 30: 771-76. 
Beveridge TH, Girard B, Kopp T, Drover JC. Yield and composition of grape seed oils extracted by supercritical carbon dioxide and petroleum ether: Varietal effects. J Agric Food Chem. 2005; 53: 1799-804.

Eren İ, Nazıroğlu M, Demirdaş A, Çelik Ö, Uğuz AC, Altunbaşak A, Ozmen I, Uz E. Venlafaxine modulates depressioninduced oxidative stress in brain and medulla of rat. Neurochem Res. 2007; 32: 497-505.

Grundmann O, Lv Y, Kelber O, Butterweck V. Mechanism of St. John's wort extract (STW3-VI) during chronic restraint stress is mediated by the interrelationship of the immune, oxidative defense, and neuroendocrine system. Neuropharmacology 2010; 58: 767-73.

Gupta S, Kashyap P, Asad M, Chattopadhyaya I, Dahiya R. Anti-depressant activity of Nyctanthes arbor-tristis in mice. Bangladesh J Pharmacol. 2016; 11: 634-45.

Guo L, Wang LH, Sun B, Yang JY, Zhao YQ, Dong YX, Spranger MI, Wu CF. Direct in vivo evidence of protective effects of grape seed procyanidin fractions and other antioxidants against ethanol-induced oxidative DNA damage in mouse brain cells. J Agric Food Chem. 2007; 55: 5881-91.

Harati E, Sadeghipour Roodsari HR, Seifi B, Kamalinejad M, Nikseresht S. The effect of oral Matricaria chamomilla extract and selenium on postpartum depression and plasma oxidant -antioxidant system in mice. Tehran Uni Med J. 2014; 71: 62534.

Ismail AF, Moawed FS, Mohamed MA. Protective mechanism of grape seed oil on carbon tetrachloride-induced brain damage in $\gamma$-irradiated rats. J Photochem Photobiol. 2015; 153: 317-23.

Kumar B, Kuhad A, Chopra K. Neuropsychopharmacological effect of sesamol in unpredictable chronic mild stress model of depression: Behavioral and biochemical evidences. Psychopharmacology 2011; 214: 819-28.

Li W, Zhang X, Wu Y, Tian X. Anti-inflammatory effect and mechanism of proanthocyanidins from grape seeds. Acta Pharmacol Sin. 2000; 22: 1117-20.

Lucca G, Comim CM, Valvassori SS, Réus GZ, Vuolo F, Petronilho F, Dal-Pizzol F, Gavioli EC, Quevedo J. Effects of chronic mild stress on the oxidative parameters in the rat brain. Neurochem Int. 2009; 54: 358-62.

Mao QQ, Ko KM, Tsai SH, Che CT. Peony glycosides produce antidepressant-like action in mice exposed to chronic unpredictable mild stress: Effects on hypothalamic-pituitaryadrenal function and brain-derived neurotrophic factor. Prog Neuropsychopharmacol Biol Psych. 2009; 33: 1211-16.

Marks W, Fournier NM, Kalynchuk LE. Repeated exposure to corticosterone increases depression-like behavior in two different versions of the forced swim test without altering nonspecific locomotor activity or muscle strength. Physiol Behav. 2009; 98: 67-72.

Momeni H, Salehi A, Seraji A. study of vitex agnus, evening primrose and vitamin $\mathrm{E}$ on body mass index (BMI). Phytochemistry 2012; 2: 25-33.

Moretti M, Colla A, de Oliveira Balen G, dos Santos DB, Budni J, de Freitas AE, Farina M, Severo Rodrigues AL. Ascorbic acid treatment, similarly to fluoxetine, reverses depressivelike behavior and brain oxidative damage induced by chronic unpredictable stress. J Psych Res. 2012; 46: 331-40.

Movahed S, Ghavami M. Comparative and identification of fatty acid composition of Iranian and importing grape seed oil. Pajouhesh Sazandegi. 2007; 3: 44-56.

Rabiei Z, Gholami M, Rafieian-Kopaei M. Antidepressant effects of Mentha pulegium in mice. Bangladesh J Pharmacol. 2016; 11: 711-15.

Rabiei Z, Rabiei S. A review on antidepressant effect of medicinal plants. Bangladesh J Pharmacol. 2017; 12: 1-11.

Sarandol A, Sarandol E, Eker SS, Erdinc S, Vatansever E, Kirli $\mathrm{S}$. Major depressive disorder is accompanied with oxidative stress: Short-term antidepressant treatment does not alter oxidative-anti-oxidative systems. Human Psychopharmacol Clin Exper. 2007; 22: 67-73.

Schaalan MF, Nassar NN. Effects of octreotide in chronically mild stressed rats: Possible role of immune and oxidative stress pathways. Neurochem Res. 2011; 36: 1717.

You Z, Luo C, Zhang W, Chen Y, He J, Zhao Q, Zuo R, Wu Y. Pro- and anti-inflammatory cytokines expression in rat's brain and spleen exposed to chronic mild stress: Involvement in depression. Behav Brain Res. 2011; 225: 135-41. 